\title{
Neuronal Apoptosis in Neurodegenerative Diseases: From Basic Research to Clinical Application
}

\author{
Pawel Kermer Jan Liman Jochen H. Weishaupt Mathias Bähr \\ Department of Neurology, University of Göttingen, Göttingen, Germany
}

\section{Key Words}

Apoptosis, neuronal · Caspases · Death effector domains $\cdot$ Neurodegeneration $\cdot$ Treatment, limitations

\begin{abstract}
In recent years, the investigation of erroneous regulation of apoptotic mechanisms during acute and chronic injury of neuronal cells has gained increasing attention. Besides acute neuronal trauma and ischemia, chronic neurodegenerative diseases like Alzheimer's, Huntington's, Parkinson's and Lou-Gehrig's disease (amyotrophic lateral sclerosis) are of particular interest. The present article will provide an overview of basic apoptotic mechanisms, the contribution of neuronal apoptosis to the above-mentioned disorders, potential clinical applications and their limitations and the possible implications for future studies regarding these neurodegenerative diseases.
\end{abstract}

Copyright $\odot 2004$ S. Karger AG, Basel

The biological phenomenon of apoptosis was initially described in 1972 by Kerr et al. [1]. Morphologically, apoptotic cell death is characterized by the succession of chromatin condensation (pyknosis), nuclear fragmentation, cell contraction and decay into small fragments sur- rounded by plasma membrane (apoptotic bodies). Apoptotic cells are opsonized in vivo by surrounding cells without accompanying inflammation, since the integrity of plasma membranes and cell organelles persists and release of intracellular components is prevented during the suicide program.

Apoptosis can occur locally, without damaging healthy adjacent cells. This is in contrast to necrotic cell death, which exhibits rapid cell swelling and subsequent rupture of the plasma membrane. Due to the inflammatory reaction as a consequence of cell rupture, necrosis usually induces substantial secondary cell damage in the surrounding tissue. Since necrosis and apoptosis differ both biochemically and structurally from each other, they were originally classified as two separate forms of cell death. In recent years though, there is increasing evidence that this distinction is not so clear and that at least traumatic cell death can be better viewed as a continuum between apoptosis and necrosis [2-5].

In a physiological context, apoptosis or programmed cell death does not only account for the maintenance of a constant size and cell number in proliferative tissues like the skin, intestinal mucosa or the immune system, but also plays a crucial role during the development of the peripheral and central nervous system. Neuronal apoptosis, for example, is pronounced at the time of the genesis of synapses [6]. Additionally, for the fate of the individual

\begin{tabular}{ll}
\hline KARGER & ( ) 2004 S. Karger AG, Basel \\
1660-2854/04/0011-0009\$21.00/0 \\
$\begin{array}{l}\text { Fax +4161306 12 34 } \\
\begin{array}{l}\text { E-Mail karger@karger.ch } \\
\text { www.karger.com }\end{array}\end{array}$ & $\begin{array}{l}\text { Accessible online at: } \\
\text { www.karger.com/ndd }\end{array}$
\end{tabular}

Dr. Pawel Kermer

Department of Neurology, University of Göttingen

Robert-Koch-Strasse 40

DE-37075 Göttingen (Germany)

Tel. +49 551394 927, Fax +49 551391 4302, E-Mail pkermer@gwdg.de 
Table 1. Key players in neuronal apoptosis

\begin{tabular}{|c|c|c|}
\hline Protein family & Members & Function \\
\hline Caspases & 14 caspases identified, 11 in the human genome & $\begin{array}{l}\text { cleave substrates at Asp residues and mediate apoptotic } \\
\text { cell death }\end{array}$ \\
\hline DED proteins & at least 12 members identified so far & $\begin{array}{l}\text { interaction of proteins of the apoptosis cascade, } \\
\text { e.g. caspase- } 8 / \text { Fadd }\end{array}$ \\
\hline DD proteins & $\begin{array}{l}\text { at least } 24 \text { members identified so far; Fadd as the most } \\
\text { prominent contains DD and DED }\end{array}$ & $\begin{array}{l}\text { interaction of proteins of the apoptosis cascade, } \\
\text { e.g. Fadd/TNF receptor family }\end{array}$ \\
\hline Cytochrome C & single protein & $\begin{array}{l}\text { released from mitochondria, forms apoptosome with } \\
\text { Apaf- } 1 \text { and caspase- } 9\end{array}$ \\
\hline Smac/Diablo & single protein & released from mitochondria, inhibits IAPs \\
\hline Bcl proteins & 25 pro- and anti-apoptotic members & $\begin{array}{l}\text { form homo-/hetero-dimers; control death program, } \\
\text { e.g. by modulating mitochondrial protein release }\end{array}$ \\
\hline BAG proteins & 6 members identified in the human genome & $\begin{array}{l}\text { e.g. bind to Bcl- } 2 \text { and Hsp } 70 \text {; link cellular stress responses } \\
\text { to the apoptotic death program }\end{array}$ \\
\hline BAR & so far no additional members identified & $\begin{array}{l}\text { binds to Bcl-2 and caspase- } 8 \text {; links extrinsic and intrinsic } \\
\text { apoptosis pathway }\end{array}$ \\
\hline BI-1 & so far no additional members identified & inhibitor of Bax-induced cell death \\
\hline CARD proteins & at least 20 members identified so far, e.g. caspases, Apaf- 1 & for example the apoptosome formation \\
\hline IAPs & $\begin{array}{l}\text { six members identified in humans; at least one is } \\
\text { expressed in neurons }\end{array}$ & inhibition of activated caspases \\
\hline
\end{tabular}

neuron, the supply of neurotrophic factors, which promote the survival and growth of nerve cells, seems to be important because such signaling will activate anti-apoptotic paths within the cell $[7,8]$.

Degeneration of one or more nerve cell populations is a major feature in many acute and chronic neurological diseases. As discussed below, many criteria for apoptotic cell death are also fulfilled during the course of chronic neurodegenerative diseases. Therefore, the development of new therapeutic strategies for the treatment of neurodegenerative diseases requires an understanding of the molecular mechanisms underlying neuronal apoptosis. Extrinsic and intrinsic apoptosis pathways and several possible avenues for crosstalk between them can be distinguished. Whereas the extrinsic pathway is initiated by cell surface activation of cytokine receptors of the tumor necrosis factor (TNF) family, the intrinsic pathway depends on the integrity and function of mitochondria within the cell [9]. Below, key proteins involved in the regulation of neuronal apoptosis will be described (table 1).

\section{Key Players in Neuronal Apoptosis}

The morphologic and biochemical changes during apoptotic cell death are mediated by a family of intracellular cysteine proteases named caspases (cysteine aspartyl-specific proteases), which cleave their substrates at aspartate residues [10]. Activation of caspases themselves also occurs by cleavage at such aspartate residues. Hence, in addition to other cellular substrates, caspases can activate themselves in a self-propagating cascade. So far, at least 14 different caspases have been identified, of which 11 have been found in the human genome [11]. They are usually divided into upstream initiator caspases and downstream effector caspases by the characteristics of their N-terminal pro-domain [9]. While initiator caspases (e.g. caspase-1, -8 and -9) can interact with other activating proteins through their long pro-domains, the short pro-domain in effector caspases up to date has no known function (e.g. caspase-3). Caspase-8, an initiator of the extrinsic signaling pathway, contains a so-called death effector domain (DED) at its N-terminus through which it interacts with and is activated by other DED proteins (at 


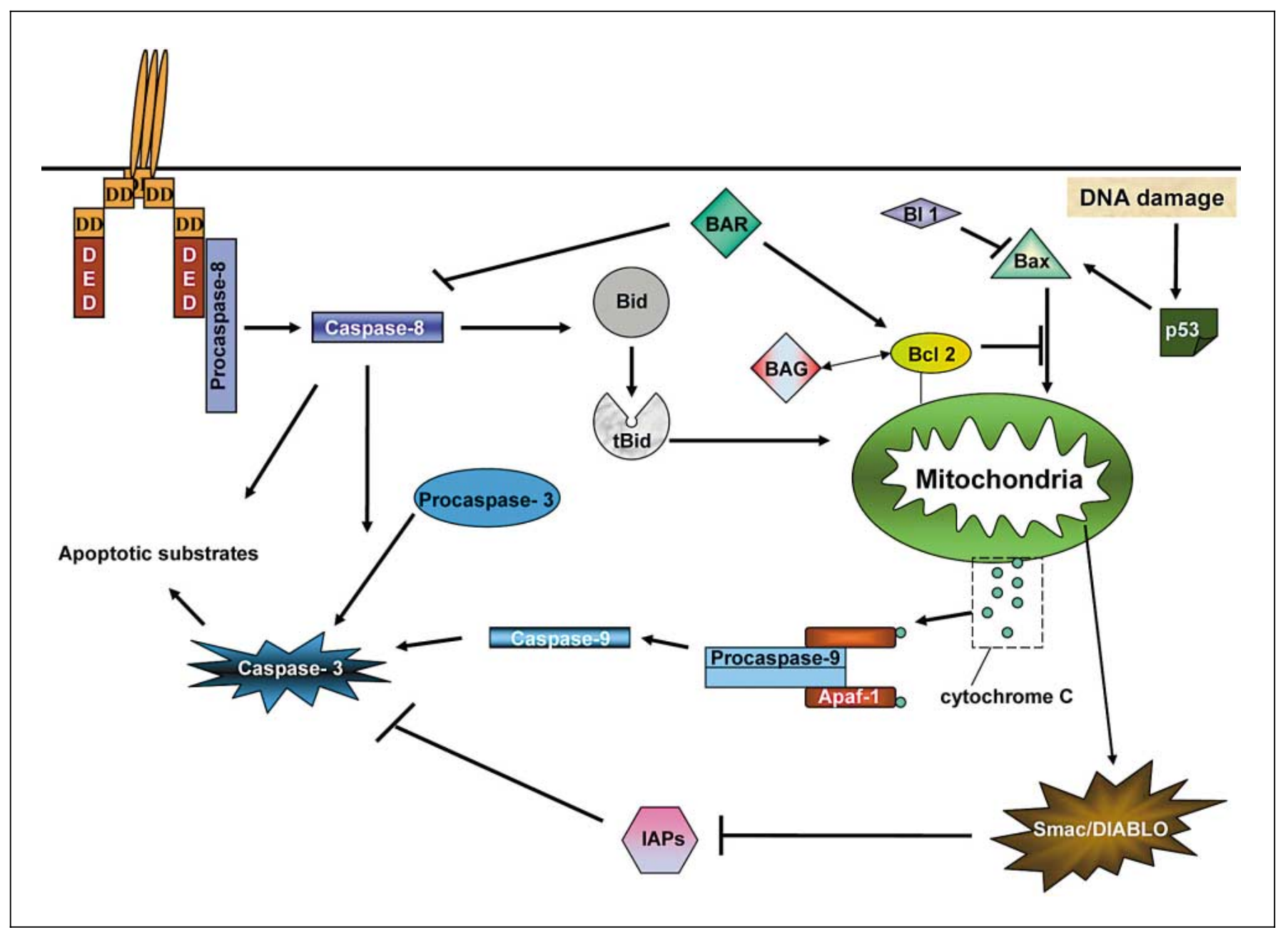

Fig. 1. Signal transduction of apoptotic cell death. The extrinsic apoptosis pathway involves receptor-mediated activation of caspase- 8 with subsequent activation of the effector caspase-3. Within the intrinsic apoptosis pathway, caspase- 3 is activated after release of cytochrome-c from mitochondria and formation of the oligomeric complex called apoptosome consisting of caspase-9, Apaf-1 and cytochrome-c. Mitochondrial pathology is controlled not only by Bcl-2 and Bcl-modulating proteins. Multiple crosstalks between the apoptosis pathways exist.

least 12 DED proteins identified so far; fig. 1). One of these DED proteins (Fadd) additionally contains a socalled death domain (DD) that has been shown to interact with death receptors of the TNF family (at least $24 \mathrm{DD}$ proteins have been identified [for review, see ref. 9]).

Although the activation of capase- 8 in neurons after different death stimuli has been described [12], the induction of neuronal apoptosis by death ligands and receptors is still controversially discussed. Interestingly, the p 75 nerve growth factor receptor ( $\mathrm{p} 75 \mathrm{NGFR}$ ) contains a modified death domain [13] and under special circumstances its activation can induce apoptosis in neurons [14]. How- ever, it has to be noted that developmental and diseasespecific induction pathways may vary significantly, particularly since adult neurons no longer show p75NGFR expression $[15,16]$.

There is considerable evidence emerging from studies in knockout and transgenic animals concerning the relevance of the intrinsic signal transduction pathway for neuronal apoptosis [17]. DNA damage (hereditary or induced), increased expression of the tumor suppressor gene $\mathrm{p} 53$, increased calcium influx by overstimulation of glutamate receptors (excitotoxicity), the damage of components of the plasma membrane, the formation of free 
radicals (oxidative stress) and metabolic stress (hypoxia, hypoglycemia), for example, can cause mitochondrial changes resulting in the formation of pores in the mitochondrial membrane (permeability transition pores) and release of several apoptosis-relevant molecules (cytochrome C, SMAC/Diablo, apoptosis-inducing factor).

Alterations in mitochondrial function that eventually lead to cell death are controlled and modulated by proteins of the $\mathrm{Bcl}-2$ family. Among the multiplicity of Bcl-2 proteins [9] there exist some with pro-apoptotic (e.g. Bax, $\mathrm{Bad}, \mathrm{Bid})$ and others with anti-apoptotic effects (e.g. Bcl$2, \mathrm{Bcl}$ XL). Formation of homo and/or hetero dimers and the equilibrium shift between pro- and anti-apoptotic members of the Bcl- 2 family may determine the sensitivity of a cell to apoptotic stimuli [18-20]. For instance, it has been shown that in neurons, the calcium-activated phosphatase calcineurin de-phosphorylates the pro-apoptotic protein $\mathrm{Bad}$, thereby initiating the apoptotic cascade [21]. In recent years, proteins binding to Bcl-2 family proteins modulating their activity have received increased attention. Among such Bcl-2 binding proteins with antiapoptotic activity is the so-called $B A G$ family [22]. So far, six members of this family have been identified in humans. All of them bind to heat shock 70 family molecular chaperones through their BAG domain and link cellular stress responses to the apoptotic death program. In neurons BAG1 was identified as a potent neuroprotectant and a regulator of neuronal differentiation [23]. In vivo, BAG1 mediates resistance against stroke, increasing Hsp70 expression on posttranscriptional levels [24]. Another Bcl-2 binding protein with neuroprotective activity is the bifunctional apoptosis regulator $(B A R)$. BAR is a multidomain protein that was first discovered as an inhibitor of Bax-induced cell death [25]. It is capable of inhibiting apoptosis induced by TNF family death receptors ('extrinsic pathway') as well as mitochondria-dependent apoptosis ('intrinsic pathway'). Interaction of BAR with Bcl-2 or Bcl-XL via an SAM domain may contribute to the anti-apoptotic properties of BAR. Moreover, the BAR protein contains a domain that is similar to classical death effector domains (termed 'pseudo DEDs') that mediate caspase- 8 binding. Therefore, BAR has been suggested to act as a scaffold protein that can bridge components of extrinsic and intrinsic apoptosis pathways. Finally, BAR is highly expressed in neurons and promotes survival after diverse apoptotic stimuli [26]. BI-1 (Bax inhibitor-1 [27]), a protein with six transmembrane domains, has emerged as potent anti-apoptotic agent in plants and was recently identified as prominent antigen in human gliomas [28]. Its function in neurons has not been uncovered yet.
Following its release from mitochondria into the cytoplasm, cytochrome-c (an enzyme of the respiratory chain) forms oligomeric complexes (apoptosomes) together with Apaf-1 (apoptotic protease activation factor-1) and caspase-9. This results in the activation of caspase-9 [29, 30]. The interaction of Apaf- 1 and caspase- 9 is mediated through a $C A R D$ domain (caspase-associated recruitment domain) contained in both proteins [31]. For the activation of caspase-9, a mechanism called 'induced proximity is believed to be responsible [32]. Through binding to Apaf-1 several inactive proforms of caspase- 9 are brought into close proximity to one another. Since the proform of this caspase possesses some protease activity, the association of multiple caspase molecules promotes cleavage and the transition into the fully active form. Apart from procaspases with a CARD domain (caspase-1, -2, -4, -5 and $-9)$, the human genome contains at least 20 CARD proteins that either boost or restrain apoptosis [9]. Active caspase- 9 cleaves and activates the effector caspase- 3 , which is responsible for driving execution of the cell death program [33].

In addition to Bcl-2 and CARD proteins with pro- or anti-apoptotic effects, there is also a family of apoptosis suppressors called IAPS (inhibitor of apoptosis proteins) with their BIR (baculovirus IAP repeat) domain. Other than viral and bacterial IAPs, which are essential for the reproduction and survival of the germs in the host organism, so far six IAPs have been identified in humans [9], of which at least one is expressed in neurons (neural apoptosis inhibitory protein). IAPs prevent the 'unintentional' activation of effector caspases, but in turn are subject to negative regulation by the mitochondrial factor Smac/ Diablo. Thereby the effective operational sequence of the apoptotic cascade after appropriate stimulation is ensured [33]. Hereditary mutations of neural apoptosis inhibitory protein with progressive degeneration of neurons are found in familial cases of spino-muscular atrophy, a motoneuron disease [34].

Moreover, there are further signalling pathways that are not directly associated with the apoptotic machinery, but nevertheless able to interfere with and restrain it. These pathways include the PI3K/Akt signalling pathway [35] and the mitogen-activated proteinkinase pathway [36]. Other anti-apoptotic signals are mediated by $c$-jun amino terminal kinase (JNK) [37] or the activation of transcription factors such as $C R E B$ (cAMP-responsive element binding protein) and $N F-\kappa B$ [for review, see ref. 6, 9, 17]. Being beyond the scope of this review, the reader is referred to more specialized articles about these pathways.

\footnotetext{
$12 \quad$ Neurodegenerative Dis 2004;1:9-19
} 


\section{Neuronal Apoptosis during Neurodegenerative Disease}

For all neurodegenerative diseases mentioned in this review, the incidence of neuronal apoptosis during the course of disease has been shown by investigations in animal and tissue culture models. Studies on postmortem human brain tissue have yielded contradictory results, because clear detection of apoptotic cells is difficult or problematic. The inability to demonstrate apoptosis in the tissues affected may be explained by the fact that cell death in these chronic illnesses occurs over decades; the suicide program in the single cell, however, is executed within a few hours $[6,38]$. Thus, synchronous detection of a substantial number of apoptotic neurons at any given time point seems almost impossible. In addition, there is a lack of studies employing drugs that interfere with the apoptotic cascade in human neurodegenerative diseases. The low specificity and selectivity of currently available anti-apoptotic substances produces undesirable adverse effects. In contrast, studies of the pathological mechanisms underlying neuronal apoptosis in hereditary forms of neurodegenerative diseases proved to be very valuable, frequently linking neuronal apoptosis with oxidative stress and mitochondrial dysfunction. Below, evidence for the involvement of apoptotic neuronal death in morbus Parkinson, morbus Huntington, morbus Alzheimer and amyotrophic lateral sclerosis (ALS) will be summarized.

\section{Morbus Parkinson}

The incidence of Parkinson's disease is about $1 / 5,000$ at an age over 50 years [39]. This disease is caused by the loss of $50-60 \%$ of dopaminergic neurons in the substantia nigra within 10-20 years, resulting in the loss of a neural control loop that becomes clinically apparent by the wellknown triad - tremor, rigor, akinesia - with a differential accentuation of these symptoms in each individual case. The dopaminergic deficit can be compensated at least temporarily by oral treatment with the dopamine precursor L-DOPA, dopamine agonists and other substances; a convincing causal therapy for the loss of neurons, however, does not exist so far.

Some studies on postmortem brain tissue of Parkinson patients have reported the presence of apoptotic cells and DNA fragmentation in the substantia nigra [40-42]. However, these findings were not confirmed by others [43, 44]. Recently, however, Hartmann et al. [45] demonstrated that caspase-3 is a critical factor for cell death in the substantia nigra of Parkinson patients. Additionally, initiator caspases seem to be strongly expressed in these neurons possibly contributing to cell death [38].

Genetic mutations in the proteins Parkin, $\alpha$-synuclein and others have been shown to contribute to the pathogenesis of familiar forms of Parkinson's disease, where undissolvable aggregates of $\alpha$-synuclein form a component of the so-called Lewy bodies [46].

The physiological function of $\alpha$-synuclein is not yet known, however it appears to play a role in the conversion of synaptic vesicles and synaptic plasticity [47]. The mutation of the Parkin gene however leads to a loss of function of the protein. As an E3-ligase, Parkin is involved in protein ubiquitination and degradation by the proteasome complex. In this regard, the observation that Parkin substrate proteins such as CDCrel-1 and synphilin- 1 can be commonly localized to Lewy bodies [47] are of particular interest. In the case of mutated $\alpha$-synuclein, it is possible that Parkin gets recruited into inclusion bodies and thereby withdrawn from the protein degradation machinery. Thus, it can be assumed that pathological accumulation of misfolded proteins in cells carrying a mutation in one of both genes leads to increased neurotoxicity. This hypothesis is supported by the observations that Parkin expression is increased under conditions of cellular stress, and that misfolded proteins, like Pael r (Parkin-associated endothelin receptor-like receptor) are removed from the endoplasmic reticulum [48]. The notion that Parkin acts as a suppressor of oxidative stress might be of critical importance for dopaminergic neurons in the substantia nigra, which are particularly vulnerable to oxidative stress [47]. The relevance of oxidative stress for the pathogenesis of Parkinson's disease is further supported by investigations showing a deficit of anti-oxidative glutathione with subsequent lack of mitochondria complex I and dopamine in nigral neurons [49, 50]. A lack of glutathione is held responsible for the damage of mitochondria with subsequent neuronal apoptosis [51].

The study of apoptotic cell death in Parkinson's disease has been advanced by the development of animal and cell culture models, in which the neurotoxins 1-methyl-4-phenyl 1,2,3,6-tetrahydropyridine (MPP+) or 6-hydroxydopamine (6-OHDA) are employed. For example, increased striatal JNK activity, a hallmark of apoptosis, was found in these models [52, 53], whereas simultaneous application of a JNK inhibitor (CEP-1347) proved to be neuroprotective [54]. Besides the activation of caspase-3 in dopaminergic neurons, increased expression of Bax could be observed in these models as well [55]. At the same time, mice overexpressing the protective Bcl-2 protein proved to be resistant to these cell death stimuli [38]. 
Interestingly, Parkin protein has recently been identified as substrate for caspase-3 [56]. The underlying cause of the disease process, however, yet has to be elucidated. Nevertheless, mitochondrial dysfunction, with subsequent initiation of the apoptotic cascade, plays an important role in almost all models for the pathogenesis of Parkinson's disease. Therefore, therapeutic stabilization of mitochondrial function or better, the complete avoidance of mitochondrial dysfunction by reduction of oxidative stress is particularly promising.

\section{Morbus Huntington}

Huntington's disease is an autosomal dominant inherited neurodegenerative illness with a prevalence of approximately 5/100,000 inhabitants in Western Europe [57]. It is accompanied by motor dysfunction, resulting in the progressive impairment of coordinated voluntary movements. Together with progressive cognitive restrictions, which are frequently leading to dementia, the illness is usually fatal within 15-20 years of onset. As cause of the illness, a mutation in the huntingtin gene could be identified. The physiological function of the huntingtin protein, however, is still unknown. The huntingtin gene mutation is characterized by surplus repeats of the trinucleotide sequence CAG coding for the amino acid glutamine, which lead to the formation of inclusion bodies and degeneration of mainly GABAergic neurons in the striatum. Individuals with 35 or less repeats are asymptomatic, whereas 36 or more CAG repeats are known to cause disease [58]. Earlier onset of the disease correlates with increased numbers of CAG repeats [59]. Up to now, there is no causal therapy.

Several observations pinpoint apoptotic neuronal death in the striatum throughout the course of Huntington's disease. Dragunow et al. [60] were the first to show DNA strand breaks in these neurons [61, 62]. However, DNA strand breaks turned out to be a non-specific marker for apoptosis. Additionally, mutated huntingtin was shown to activate the JNK signaling pathway leading to subsequent neuronal apoptosis [63]. Excitotoxicity is also considered a pathogenetic factor in Huntington's disease. If excitatory amino acids such as kainate are injected into the striatum, animals develop symptoms similar to that observed in Huntington's disease [57, 64, 65]. Moreover, huntingtin has been demonstrated to be a substrate for the effector caspase-3, with the polyglutamine sequence in the mutated protein being favored for cleavage by caspases [66] ultimately resulting in cleaved molecules with increased neurotoxicity [67]. With regard to caspases, the inhibition of caspase- 1 proved to be of benefit during the course of the disease in a mouse Huntington model [68]. Recently, it has been shown that mutated huntingtin has a decreased affinity for its binding partner Hip-1 (Huntingtin interacting protein-1 [69]). Free Hip-1 interacts with HIPPI (Hip-1 protein interactor) via its pseudo-DED domain and additionally binds the DED protein caspase8 in a complex, whereby the apoptotic cascade is possibly initiated [70]. Since there is no causal treatment for Huntington's disease so far, modulation of the apoptotic cascade is considered a promising therapeutic intervention.

\section{Amyotrophic Lateral Sclerosis}

ALS (Lou-Gehrig's disease) is one of the most frequently occurring motoneuron diseases with adult onset (incidence 1-2 per 100,000 [5]). ALS is characterized by a progressive loss of motoneurons in the cortex and the ventral horn of the spinal cord. Progressive paralyses of all extremities as well as respiratory and sip musculature lead to death within 3-5 years after onset. The disease usually occurs sporadically.

As is the case in other neurodegenerative diseases, oxidative stress, the overactivation of glutamate receptors, and calcium overload are considered possible causative mechanisms [6]. In autosomal-dominant inherited cases (approximately $5 \%$ of all ALS patients) a mutation in the gene coding for superoxide dismutase could be identified. This enzyme physiologically exerts anti-oxidative and cytoprotective effects acting as free radical scavenger. There are four different hypotheses, how superoxide dismutase can act neurotoxic [71]: (1) the formation of hydroxyl radicals; (2) the nitrosylation of tyrosine residues in proteins by peroxynitrite derivates; (3) copper and zinc toxicity, and (4) pathological protein aggregation with the formation of inclusion bodies. Nonetheless, these current hypotheses all point to increased oxidative stress, leading to mitochondrial dysfunction and the activation of the intrinsic apoptosis cascade in the respective neurons. Increased expression of the pro-apoptotic protein Bax, with a concurrent decrease in the expression of Bcl-2, as well as DNA fragmentation have been found in transgenic mouse models of ALS, and in the spinal cord ventral horn and the motor cortex of individuals that had died from ALS [71-74]. Furthermore, increased caspase- 1 and -3 activity has been found in the motor cortex and spinal cords of patients $[75,76]$. In addition, active caspase-3 was detected selectively in ventral horn neurons of those individuals [77]. The involvement of the apoptotic cascade in ALS is further underscored by findings that caspase inhibitors were neuroprotective both in animal and tissue culture models of the disease [71]. Finally, a contribution of 
the p53 tumor suppressor gene to the degeneration of motoneurons has been proposed; however, this notion is controversial.

\section{Morbus Alzheimer}

Dementia of the Alzheimer type affects about 10\% of the population over 65 years of age and up to $50 \%$ over 85 years of age [78]. Degeneration of neurons in the basal forebrain, hippocampus and cortex is a hallmark of Alzheimer's disease. Besides decreased synaptic density and the loss of neurons, the brains of Alzheimer patients show characteristic histological changes at the neuronal level, i.e. the formation of so-called senile plaques, consisting of aggregates of the $\beta$-amyloid protein, and tangles, which occur through the accumulation of hyperphosphorylated tau, a protein associated with microtubuli. Although the number of neurons showing these characteristics is too small to explain the dysfunction and death of so many neurons in Alzheimer brains, changes in $\beta$-amyloid metabolism are believed to play a predominant role in the observed pathology. $\beta$-Amyloid is generated by cleavage of amyloid precursor protein, which is mutated in a hereditary form of Alzheimer's disease. Exposure to $\beta$ amyloid induces apoptosis in neurons. Cell death is preceded by the activation of caspases and altered expression levels of Bcl-2 family proteins [79, 80]. The mechanisms by which $\beta$-amyloid induces cell death include the peroxidation of membrane lipids, oxidative stress induced by calcium influx, and mitochondrial dysfunction [6]. In other forms of familial Alzheimer's disease, mutations in the presenilin gene 1 and 2 were identified. These mutations also alter the normal proteolytic cleavage of amyloid precursor protein, sensitizing neuronal cells to apoptotic stimuli in vitro. However, results from transgenic mice overexpressing either amyloid precursor protein or presenilins remain contradictory with respect to the functional relevance of these proteins in Alzheimer's dementia [79]. Nevertheless, the altered degradation and pathological aggregation of mutated proteins, with consecutive activation of the apoptosis machinery seem to be crucial for neuronal death in Alzheimer's models.

Reduced expression of the neurotrophic factors NGF and BDNF were found in postmortem studies on brains of Alzheimer patients [81, 82]. Decreases in the endogenous levels of neurotrophic factors have been shown to increase the susceptibility of neurons to oxidative stress, and have been attributed to lowered synaptic density. As is the case with other neurodegenerative illnesses, the presence of DNA fragmentation, caspase activation, and the expression of other apoptosis-related genes has been described [80]. However, particularly in Alzheimer's disease, the current data are contradictory [79]. For example, it is still unclear whether the apoptotic process is directly responsible for the death of neurons. Although apoptosis may not be the primary cause of neuronal degeneration in Alzheimer's disease, programmed cell death may contribute to the continued progression of disease pathology [79]. Thus, interfering with apoptosis is still of interest as a potential therapeutic strategy in light of the fact that current treatments for Alzheimer's disease are mainly symptomatic and rather inefficient.

\section{Transfer of Knowledge from Bench to Bedside - Limitations and Perspectives: Therapeutic Strategies and Their Problems}

For all the neurodegenerative diseases mentioned above, tissue culture and animal models do exist, reproducing some of the pathophysiological characteristics of the respective disease. These models range from the application of neurotoxins to cultured cells, the administration of toxins to animals, and the use of lesion models in transgenic animals. However, from the multitude of anti-apoptotic substances that have been tested in basic research models, few have reached clinical testing in patients thus far (fig. 2). Among these substances are neurotrophic factors, mitochondria-stabilizing agents, anti-oxidants, antitoxins, antibiotics, glutamate receptor and calcium channel blockers as well as caspase inhibitors [83].

One anti-apoptotic drug that has recently been approved for clinical use is Akatinol ${ }^{\circledR}$ (memantine). Originally released for the treatment of Parkinson's disease and dementia more than 10 years ago [84], this drug has experienced a renaissance after being tested successfully in an US phase III trial for the treatment of severe Alzheimer's disease. Memantine is classified as a non-competitive inhibitor of the NMDA-type glutamate receptor that has been shown to interfere with glutamate-induced apoptosis and processes of learning and memory. Currently, derivates are being developed in order to optimize neuroprotective benefits and minimize adverse effects.

Of course, we have to ask why so many promising drugs that are effective in basic research models fail to improve the outcome of neurodegenerative diseases in humans. First, patients and clinicians have to deal with adverse drug-related side effects. Although, clinicians may attempt to balance the positive and negative therapeutic effects of medication, unwanted side effects can lead to low compliance by patients which has previously 
Fig. 2. Transfer of knowledge from bench to bedside. Summary of problems and limitations with the implementation of new therapeutic strategies in the clinic based on basic research findings. Possible solutions are outlined as discussed in the text.

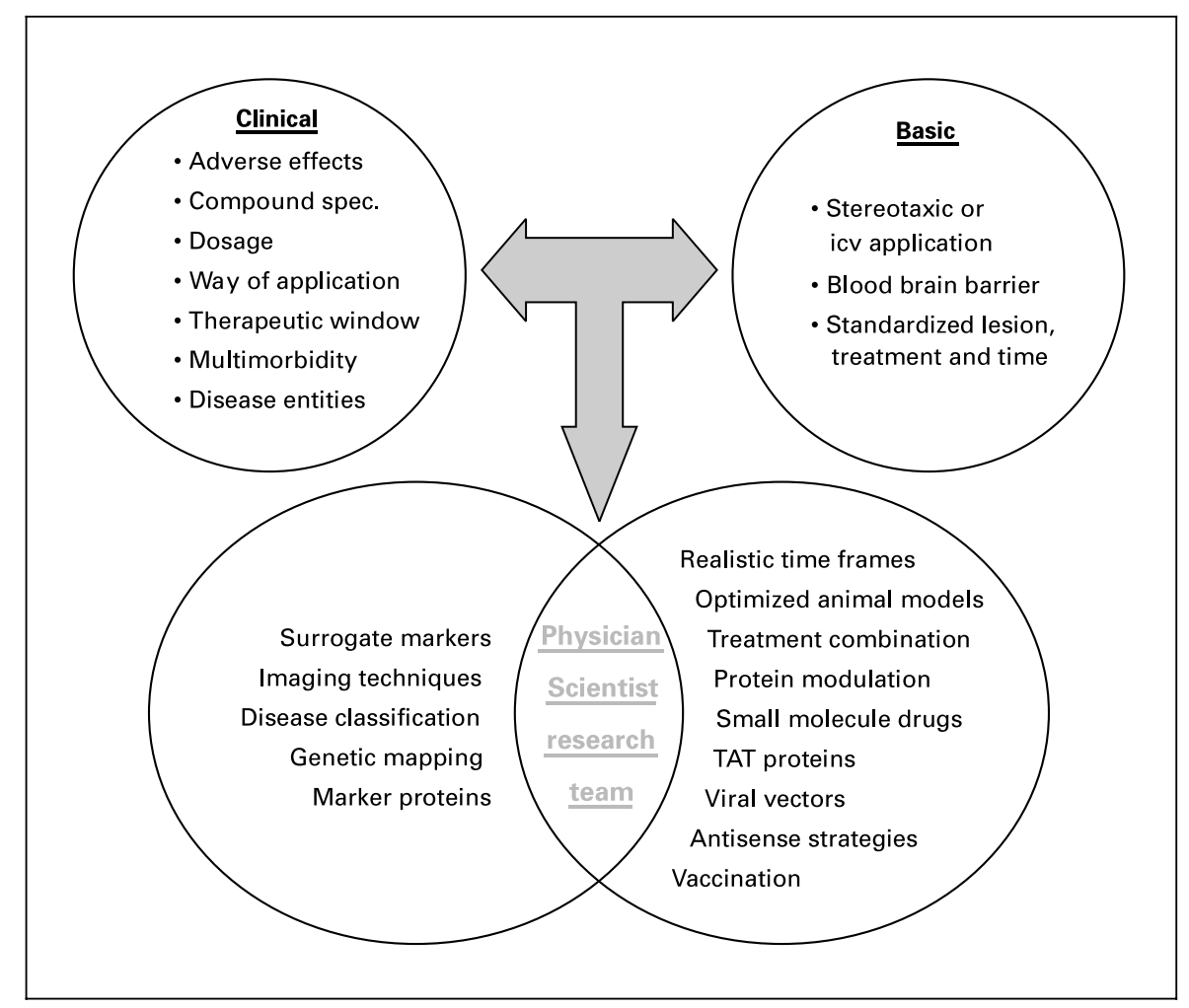

been attributed to the failure of many phase I and II clinical trials. The profiles of positive and negative effects of therapeutic interventions are closely related to the specificity of the compounds, the applied dosage, and the route of application. Drug effects at sites distant from the desired location may limit the therapeutic benefits due to the inability to achieve adequate concentrations of the medication in the brain without intoxicating the rest of the body. The blood brain barrier in humans represents the most difficult obstacle to CNS drug delivery, and in particular, the administration of larger molecular-weight drugs. Moreover, drugs may be broken down or inactivated in the periphery of the body if injected intravenously or orally administered. These problems rarely arise in animal models, where the drug is usually applied by stereotaxic injection into the ventricles or close to the site of injury.

Beyond the impractical method of drug administration in animals, animal models of disease tend to have more reproducible and standardized temporal profiles, lesion extents, and therapeutic outcomes. In addition, the animals that develop disease are for the most part otherwise healthy. To the contrary, patients in the clinical setting are often multi-morbid and treated with multiple drugs, thereby significantly narrowing treatment options for physicians.

Another problem to be considered is the therapeutic window. Usually, in animal models, drugs are applied early after lesioning, at the onset of disease or before symptoms occur. While these models contribute to the understanding of the molecular mechanisms of neurodegeneration and provide a general basis for therapeutic strategies, they are less helpful regarding drug application in a clinical setting. A closer look at Parkinson's disease, for example, immediately illustrates several limitations of animal models. Patients usually develop symptoms when the number of dopaminergic neurons in the substantia nigra has decreased by $60-80 \%$, with the slow process of neuronal degeneration already lasting for years [38]. Thus, our therapeutic goal is not the rescue of affected cells but rather the preservation of the remaining neurons. Additional difficulties arise from the existence of diverse forms of Parkinson's disease based on differential diagnoses. We can distinguish hereditary forms, idiopathic forms where the cause is not known, toxic forms resulting from poisoning, and a form of the disease that is embedded in syndromes where neuronal degeneration not only occurs in the substantia nigra but also in other independent brain 
regions at the same time (multiple system atrophy [85]). In addition, from a histological point of view, considerable variability in terms of the formation of cellular inclusion bodies (Lewy bodies) has been observed in humans. It seems reasonable to speculate that, while sharing the same or at least similar symptoms, all these forms of Parkinson's disease represent different entities, following different pathophysiological pathways and consequently requiring specific treatment. Nonetheless, common apoptotic pathways may be shared regardless of the upstream death initiator, permitting the development of broadly applicable therapeutic strategies.

\section{Perspectives}

We have outlined some of the limitations of translating basic research to clinical applications. Now we have to consider how the current approach to the scientific and clinical handling of neurodegenerative diseases can be optimized and focused, thereby facilitating the transfer from what we learn at the bench to what we do at the bedside. Doubtless, interdisciplinary interactions merit some improvement. Building up research teams consisting of basic scientists, physician scientists, clinicians, and possibly individuals not related to the field should enable us to work out strategies for a better experimental design in the laboratory, and accelerate the transfer of knowledge to the clinic. Close contacts with the biotechnology and pharmaceutical industry are necessary to enhance the implementation of new therapeutic strategies in large clinical trials.

In the future, animal models have to be improved in order to more closely approximate human disease. Lesion models and neuroprotective strategies should be adjusted to fit realistic time frames and procedures that reflect available treatment avenues in the hospital. Instead of testing yet another drug that acts on a cytoprotective pathway previously analyzed, one might consider combining neuroprotective agents that act on different pathways or at different levels of the same signal transduction pathway. Ultimately, results obtained through such studies might enable us to reduce the adverse effects observed in clinical applications, by decreasing the dosage of a single drug while still benefiting from additive effects of the drug combination. The reduction of undesirable drug properties can also be achieved by altering the binding characteristics of a protein, deleting or adding domains, or mutating binding sites. The ultimate goal of protein modification is the generation of small synthetic drugs that can mimic the protective effects of natural proteins but avoid the negative ones entirely. The engineering of new molecules may also be useful for circumventing the current problem with respect to targeted drug delivery. The intact blood-brain barrier prevents proteins from entering the brain. Obviously, surgical approaches to bypass this barrier are only feasible in a small number of patients. Consequently, the design of compounds bearing moieties facilitating the transport into the central nervous system (e.g. TAT proteins [86-88]) represents a promising alternative. Moreover, genetically modified viral vectors appear to be useful tools to get therapeutic agents where they are needed $[55,89]$. Antisense knockdown strategies that lower the expression of disease-associated genes, if specific enough, represent another approach for the treatment of hereditary neurodegenerative diseases where mutated proteins are held responsible for their pathophysiology [90]. As an alternative treatment option that still has to be optimized, first studies in Alzheimer patients have been launched employing vaccination against pathological proteins [91].

In the clinical setting, new surrogate markers for disease progression and therapy monitoring are required. At present, studies involving patients make use of clinical parameters (scales, mortality) as outcome measures, and these are less accurate than the parameters used in animal models. Defining such markers on the basis of the different processes that lead to neuronal degeneration and the application of new imaging techniques in vivo would also be helpful to revise the current classifications of neurodegenerative diseases. By intensifying research on genetic mapping and potential marker proteins, we may be able to uncover new criteria for regrouping or reclassifying diseases. Hopefully, we will soon be able to provide every patient suffering from neurodegenerative disease with a more specified and diversified therapy taking into account individual symptoms as well as histology and pathophysiology. Then, the apparent gap between the bench and bedside may not remain as wide as it is today. 


\section{References}

1 Kerr JF, Wyllie AH, Currie AR: Apoptosis: A basic biological phenomenon with wide-ranging implications in tissue kinetics. Br J Cancer 1972;26:239-257.

-2 Portera-Cailliau C, Price DL, Martin LJ: Excitotoxic neuronal death in the immature brain is an apoptosis-necrosis morphological continuum. J Comp Neurol 1997;378:70-87.

73 Portera-Cailliau C, Price DL, Martin LJ: NonNMDA and NMDA receptor-mediated excitotoxic neuronal deaths in adult brain are morphologically distinct: Further evidence for an apoptosis-necrosis continuum. J Comp Neurol 1997;378:88-104.

$\checkmark 4$ Martin LJ, Al-Abdulla NA, Brambrink AM, Kirsch JR, Sieber FE, Portera-Cailliau C: Neurodegeneration in excitotoxicity, global cerebral ischemia, and target deprivation: A perspective on the contributions of apoptosis and necrosis. Brain Res Bull 1998;46:281-309.

$\checkmark 5$ Martin LJ: Neuronal cell death in nervous system development, disease, and injury. Int $\mathrm{J}$ Mol Med 2001;7:455-478.

$\checkmark 6$ Mattson MP: Apoptosis in neurodegenerative disorders. Nat Rev Mol Cell Biol 2000;1:120 129

7 Barde YA: Trophic factors and neuronal survival. Neuron 1989;2:1525-1534.

8 Mattson MP, Lindvall O: Neurotrophic factor and cytokine signaling in the aging brain; in Mattson MP, Geddes JW (eds): The Aging Brain. Greenwich, JAI Press, 1997, pp 299 345.

$>9$ Reed JC: Mechanisms of apoptosis. Am J Pathol 2000; 157:1415-1430.

10 Alnemri ES, Livingston DJ, Nicholson DW, Salvesen G, Thornberry NA, Wong WW, Yuan $\mathrm{J}$ : Human ICE/CED-3 protease nomenclature. Cell 1996;87:171.

$\$ 11$ Reed JC: Apoptosis-based therapies. Nat Rev Drug Discov 2002;11:111-121.

$\checkmark 12$ Velier JJ, Ellison JA, Kikly KK, Spera PA, Barone FC, Feuerstein GZ: Caspase- 8 and caspase- 3 are expressed by different populations of cortical neurons undergoing delayed cell death after focal stroke in the rat. $\mathrm{J}$ Neurosci 1999; 19:5932-5941.

$\checkmark 13$ Liepinsh E, Ilag LL, Otting G, Ibanez CF: NMR structure of the death domain of the p75 neurotrophin receptor. EMBO J 1997;16: 4999-5005.

14 Bredesen DE, Ye X, Tasinato A, Sperandio S, Wang JJ, Assa-Munt N, Rabizadeh S: p75NTR and the concept of cellular dependence: Seeing how the other half die. Cell Death Differ 1998; 5:365-371.

15 Hu B, Yip HK, So KF: Localization of p75 neurotrophin receptor in the retina of the adult SD rat: An immunocytochemical study at light and electron microscopic levels. Glia 1998;24:187197

16 Hirsch S, Labes M, Bahr M: Changes in BDNF and neurotrophin receptor expression in degenerating and regenerating rat retinal ganglion cells. Restor Neurol Neurosci 2000;17:125134.

17 Yuan J, Yankner BA: Apoptosis in the nervous system. Nature 2000;407:802-809.
18 Kroemer G, Reed JC: Mitochondrial control of cell death. Nat Med 2000;6:513-519.

19 Reed JC: Cytochrome c: Can't live with it Can't live without it. Cell 1997;91:559-562.

20 Reed JC: Bcl-2 family proteins. Oncogene 1998; 17:3225-3236.

21 Wang HG, Pathan N, Ethell IM, Krajewski S, Yamaguchi Y, Shibasaki F, McKeon F, Bobo T, Franke TF, Reed JC: $\mathrm{Ca}^{2+}$-induced apoptosis through calcineurin dephosphorylation of BAD. Science 1999;284:339-343.

22 Takayama S, Reed JC: Molecular chaperone targeting and regulation by BAG family proteins. Nat Cell Biol 2001;3:E237-E241.

23 Kermer P, Krajewska M, Zapata JM, Takayama S, Mai J, Krajewski S, Reed JC: Bag1 is a regulator and marker of neuronal differentiation. Cell Death Differ 2002;9:405-413.

24 Kermer P, Digicaylioglu MH, Kaul M, Zapata JM, Krajewska M, Stenner-Liewen F, Takayama S, Krajewski S, Lipton SA, Reed JC: BAG1 over-expression in the mouse brain protects against stroke. Brain Pathol 2003;13:495-506.

25 Zhang H, Xu Q, Krajewski S, Krajewska M, Xie Z, Fuess S, Kitada S, Pawlowski K, Godzik A, Reed JC: BAR: An apoptosis regulator at the intersection of caspases and Bcl-2 family proteins. Proc Natl Acad Sci USA 2000;97:25972602.

26 Roth W, Kermer P, Krajewska M, Krajewski S, Reed JC: Bifunctional apoptosis regulator (BAR) protects neurons from diverse cell death pathways. Cell Death Differ 2003;10:11781187.

27 Xu Q, Reed JC: Bax inhibitor-1, a mammalian apoptosis suppressor identified by functional screening in yeast. Mol Cell 1998;1:337-346.

28 Schmits R, Cochlovius B, Treitz G, Regitz E, Ketter R, Preuss KD, Romeike BF, Pfreundschuh $\mathrm{M}$ : Analysis of the antibody repertoire of astrocytoma patients against antigens expressed by gliomas. Int J Cancer 2002;98:7377.

29 Li P, Nijhawan D, Budihardjo I, Srinivasula SM, Ahmad M, Alnemri ES, Wang X: Cytochrome $\mathrm{c}$ and dATP-dependent formation of Apaf-1/caspase-9 complex initiates an apoptotic protease cascade. Cell 1997;91:479-489.

30 Zou H, Li Y, Liu X, Wang X: An APAF-1 cytochrome c multimeric complex is a functional apoptosome that activates procaspase-9. J Biol Chem 1999;274:11549-11556.

31 Qin H, Srinivasula SM, Wu G, FernandesAlnemri T, Alnemri ES, Shi Y: Structural basis of procaspase-9 recruitment by the apoptotic protease activating factor 1 . Nature 1999;399: 549-557.

32 Salvesen GS, Dixit VM: Caspase activation: The induced-proximity model. Proc Natl Acad Sci USA 1999;96:10964-10967.

33 Hengartner MO: The biochemistry of apoptosis. Nature 2000;407:770-776.

34 Roy N, Mahadevan MS, McLean M, Shutler G, Yaraghi Z, Farahani R, Baird S, BesnerJohnston A, Lefebvre C, Kang X, et al: The gene for neuronal apoptosis inhibitory protein is partially deleted in individuals with spinal muscular atrophy. Cell 1995;80:167-178.
Franke TF, Kaplan DR, Cantley LC: PI3K: Downstream AKTion blocks apoptosis. Cell 1997;88:435-437.

36 Fukunaga K, Miyamoto E: Role of MAP kinase in neurons. Mol Neurobiol 1998;16:79-95

37 Bozyczko-Coyne D, Saporito MS, Hudkins RL: Targeting the JNK pathway for therapeutic benefit in CNS disease. Curr Drug Target CNS Neurol Disord 2002;1:31-49.

38 Andersen JK: Does neuronal loss in Parkinson's disease involve programmed cell death? Bioessays 2001;23:640-646.

39 Fischer PP: Parkinson's disease and the U.S. health care system. J Community Health Nurs 1999;16:191-204.

40 Mochizuki H, Goto K, Mori H, Mizuno Y: Histochemical detection of apoptosis in Parkinson's disease. J Neurol Sci 1996;137:120-123.

41 Anglade P, Vyas S, Javoy-Agid F, Herrero MT, Michel PP, Marquez J, Mouatt- Prigent A, Ruberg M, Hirsch EC, Agid Y: Apoptosis and autophagy in nigral neurons of patients with Parkinson's disease. Histol Histopathol 1997; 12:25-31.

42 Hirsch EC, Hunot S, Faucheux B, Agid Y, Mizuno Y, Mochizuki H, Tatton WG, Tatton N, Olanow WC: Dopaminergic neurons degenerate by apoptosis in Parkinson's disease. Mov Disord 1999; 14:383-385.

43 Banati RB, Daniel SE, Blunt SB: Glial pathology but absence of apoptotic nigral neurons in long-standing Parkinson's disease. Mov Disord 1998;13:221-227.

44 Wüllner U, Kornhuber J, Weller M, Schulz JB Loschmann PA, Riederer P, Klockgether T: Cell death and apoptosis regulating proteins in Parkinson's disease - A cautionary note. Acta Neuropathol (Berl) 1999;97:408-412.

45 Hartmann A, Hunot S, Michel PP, Muriel MP Vyas S, Faucheux BA, Mouatt-Prigent A, Turmel H, Srinivasan A, Ruberg M, Evan GI, Agid Y, Hirsch EC: Caspase-3: A vulnerability factor and final effector in apoptotic death of dopaminergic neurons in Parkinson's disease. Proc Natl Acad Sci USA 2000;97:2875-2880.

46 Polymeropoulos MH: Genetics of Parkinson's disease. Ann NY Acad Sci 2000;920:28-32.

47 Giasson BI, Lee VM: Parkin and the molecular pathways of Parkinson's disease. Neuron 2001; 31:885-888.

48 Imai Y, Soda M, Inoue H, Hattori N, Mizuno Y, Takahashi R: An unfolded putative transmembrane polypeptide, which can lead to endoplasmic reticulum stress, is a substrate of Parkin. Cell 2001;105:891-902.

49 Perry TL, Yong VW: Idiopathic Parkinson's disease, progressive supranuclear palsy and glutathione metabolism in the substantia nigra of patients. Neurosci Lett 1986;67:269-274.

50 Jenner P, Olanow CW: Understanding cell death in Parkinson's disease. Ann Neurol 1998; 44(3 suppl 1):S72-S84.

51 Merad-Boudia M, Nicole A, Santiard-Baron D, Saille C, Ceballos-Picot I: Mitochondrial impairment as an early event in the process of apoptosis induced by glutathione depletion in neuronal cells: Relevance to Parkinson's disease. Biochem Pharmacol 1998;56:645-655. 
-52 Nishi K: Expression of c-Jun in dopaminergic neurons of the substantia nigra in 1-methyl-4phenyl-1,2,3,6-tetrahydropyridine (MPTP) treated mice. Brain Res 1997;771:133-141.

$\checkmark 53$ Saporito MS, Thomas BA, Scott RW: MPTP activates c-Jun $\mathrm{NH}(2)$-terminal kinase (JNK) and its upstream regulatory kinase MKK4 in nigrostriatal neurons in vivo. $\mathrm{J}$ Neurochem 2000;75:1200-1208

-54 Saporito MS, Brown EM, Miller MS, Carswell S: CEP-1347/KT-7515, an inhibitor of c-jun N-terminal kinase activation, attenuates the 1-methyl-4-phenyl tetrahydropyridine-mediated loss of nigrostriatal dopaminergic neurons In vivo. $\mathbf{J}$ Pharmacol Exp Ther 1999;288:421-427.

-55 Eberhardt O, Coelln RV, Kugler S, Lindenau J, Rathke-Hartlieb S, Gerhardt E, Haid S, Isenmann S, Gravel C, Srinivasan A, Bahr M, Weller M, Dichgans J, Schulz JB: Protection by synergistic effects of adenovirus-mediated $\mathrm{X}$ chromosome-linked inhibitor of apoptosis and glial cell line-derived neurotrophic factor gene transfer in the 1-methyl-4-phenyl-1,2,3,6-tetrahydropyridine model of Parkinson's disease. J Neurosci 2000;20:9126-9134.

-56 Kahns S, Lykkebo S, Jakobsen LD, Nielsen MS, Jensen PH: Caspase-mediated parkin cleavage in apoptotic cell death. J Biol Chem 2002;277:15303-15308.

$\checkmark 57$ Ho LW, Carmichael J, Swartz J, Wyttenbach A, Rankin J, Rubinsztein DC: The molecular biology of Huntington's disease. Psychol Med 2001;31:3-14

-58 Rubinsztein DC, Leggo J, Coles R, Almqvist E, Biancalana V, Cassiman JJ, Chotai K, Connarty M, Crauford D, Curtis A, Curtis D, Davidson MJ, Differ AM, Dode C, Dodge A, Frontali M, Ranen NG, Stine OC, Sherr M, Abbott MH, Franz ML, Graham CA, Harper PS, Hedreen JC, Hayden MR, et al: Phenotypic characterization of individuals with 30-40 CAG repeats in the Huntington disease (HD) gene reveals HD cases with 36 repeats and apparently normal elderly individuals with 36-39 repeats. Am J Hum Genet 1996;59:16-22.

59 Ross CA, Hayden MR: Huntington's disease; in Rubinsztein DC, Hayden MR (eds): Analysis of Triplet Repeat Disorders. Oxford, Bios Scientific, 1998, pp 169-208.

60 Dragunow M, Faull RL, Lawlor P, Beilharz EJ Singleton K, Walker EB, Mee E: In situ evidence for DNA fragmentation in Huntington's disease striatum and Alzheimer's disease temporal lobes. Neuroreport 1995;6:1053-1057.

-61 Portera-Cailliau C, Hedreen JC, Price DL, Koliatsos VE: Evidence for apoptotic cell death in Huntington disease and excitotoxic animal models. J Neurosci 1995;15(5 Pt 2):37753787.

62 Thomas LB, Gates DJ, Richfield EK, O’Brien TF, Schweitzer JB, Steindler DA: DNA end labeling (TUNEL) in Huntington's disease and other neuropathological conditions. Exp Neurol 1995; 133:265-272.

63 Liu YF: Expression of polyglutamine-expanded Huntingtin activates the SEK1-JNK pathway and induces apoptosis in a hippocampal neuronal cell line. J Biol Chem 1998;273. 28873-28877.
64 Davies S, Ramsden DB: Huntington's disease. Mol Pathol 2001;54:409-413.

65 Sieradzan KA, Mann DM: The selective vulnerability of nerve cells in Huntington's disease. Neuropathol Appl Neurobiol 2001;27:121.

66 Goldberg YP, Nicholson DW, Rasper DM, Kalchman MA, Koide HB, Graham RK, Bromm M, Kazemi-Esfarjani P, Thornberry NA, Vaillancourt JP, Hayden MR: Cleavage of huntingtin by apopain, a proapoptotic cysteine protease, is modulated by the polyglutamine tract. Nat Genet 1996;13:442-449.

67 Wellington CL, Ellerby LM, Hackam AS, Margolis RL, Trifiro MA, Singaraja R, McCutcheon K, Salvesen GS, Propp SS, Bromm M, Rowland KJ, Zhang T, Rasper D, Roy S, Thornberry N, Pinsky L, Kakizuka A, Ross CA, Nicholson DW, Bredesen DE, Hayden MR: Caspase cleavage of gene products associated with triplet expansion disorders generates truncated fragments containing the polyglutamine tract. J Biol Chem 1998;273:91589167.

-68 Ona VO, Li M, Vonsattel JP, Andrews LJ, Khan SQ, Chung WM, Frey AS, Menon AS, Li XJ, Stieg PE, Yuan J, Penney JB, Young AB, Cha JH, Friedlander RM: Inhibition of caspase-1 slows disease progression in a mouse model of Huntington's disease. Nature 1999; 399:263-267.

-69 Kalchman MA, Koide HB, McCutcheon K, Graham RK, Nichol K, Nishiyama K, KazemiEsfarjani P, Lynn FC, Wellington C, Metzler M, Goldberg YP, Kanazawa I, Gietz RD, Hayden MR: HIP1, a human homologue of $S$. cerevisiae Sla2p, interacts with membrane-associated huntingtin in the brain. Nat Genet 1997;16:44-53.

70 Gervais FG, Singaraja R, Xanthoudakis S, Gutekunst CA, Leavitt BR, Metzler M, Hackam AS, Tam J, Vaillancourt JP, Houtzager V, Rasper DM, Roy S, Hayden MR, Nicholson DW: Recruitment and activation of caspase- 8 by the Huntingtin-interacting protein Hip-1 and a novel partner Hippi. Nat Cell Biol 2002;4:95105.

71 Sathasivam S, Ince PG, Shaw PJ: Apoptosis in amyotrophic lateral sclerosis: A review of the evidence. Neuropathol Appl Neurobiol 2001; 27:257-274.

72 Troost D, Aten J, Morsink F, de Jong JM: Apoptosis in amyotrophic lateral sclerosis is not restricted to motor neurons. Bcl-2 expression is increased in unaffected post-central gyrus. Neuropathol Appl Neurobiol 1995;21: 498-504.

$73 \mathrm{Mu}$ X, He J, Anderson DW, Trojanowski JQ, Springer JE: Altered expression of bcl-2 and bax mRNA in amyotrophic lateral sclerosis spinal cord motor neurons. Ann Neurol 1996;40: 379-386.

74 Ekegren T, Grundstrom E, Lindholm D, Aquilonius SM: Upregulation of Bax protein and increased DNA degradation in ALS spinal cord motor neurons. Acta Neurol Scand 1999;100: 317-321.
75 Martin LJ: Neuronal death in amyotrophic lateral sclerosis is apoptosis: Possible contribution of a programmed cell death mechanism. J Neuropathol Exp Neurol 1999;58:459-471.

76 Li M, Ona VO, Guegan C, Chen M, JacksonLewis V, Andrews LJ, Olszewski AJ, Stieg PE, Lee JP, Przedborski S, Friedlander RM: Functional role of caspase- 1 and caspase- 3 in an ALS transgenic mouse model. Science 2000; 288:335-339.

77 Vukosavic S, Stefanis L, Jackson-Lewis V, Guegan C, Romero N, Chen C, Dubois-Dauphin M, Przedborski S: Delaying caspase activation by Bcl-2: A clue to disease retardation in a transgenic mouse model of amyotrophic lateral sclerosis. J Neurosci 2000;20:9119-9125.

78 Antuono P, Beyer J: The burden of dementia. A medical and research perspective. Theor Med Bioeth 1999;20:3-13.

79 Roth KA: Caspases, apoptosis, and Alzheimer disease: Causation, correlation, and confusion. J Neuropathol Exp Neurol 2001;60:829-838.

80 Mattson MP, Duan W, Pedersen WA, Culmsee $\mathrm{C}$ : Neurodegenerative disorders and ischemic brain diseases. Apoptosis 2001;6:69-81.

81 Phillips HS, Hains JM, Armanini M, Laramee GR, Johnson SA, Winslow JW: BDNF mRNA is decreased in the hippocampus of individuals with Alzheimer's disease. Neuron 1991;7:695702.

82 Mufson EJ, Kordower JH: Cortical neurons express nerve growth factor receptors in advanced age and Alzheimer disease. Proc Natl Acad Sci USA 1992;89:569-573.

83 Kermer P, Bähr M: Prävention neuronaler Apoptose: Implikationen für die Therapie neurodegenerativer Erkrankungen. Neuroforum 2002;2:193-199.

84 Gortelmeyer R, Erbler H: Memantine in the treatment of mild to moderate dementia syndrome. A double-blind placebo-controlled study. Arzneimittelforschung 1992;42:904913.

85 Oertel WH, Bandmann O: Multiple system atrophy. J Neural Transm Suppl 1999;56:155164

86 Becker-Hapak M, McAllister SS, Dowdy SF: TAT-mediated protein transduction into mammalian cells. Methods 2001;24:247-256.

87 Ford KG, Souberbielle BE, Darling D, Farzaneh F: Protein transduction: An alternative to genetic intervention? Gene Ther 2001;8:1-4.

88 Kilic U, Kilic E, Dietz GP, Bähr M: Intravenous TAT-GDNF is protective after focal cerebral ischemia in mice. Stroke 2003;34:13041310.

89 Baekelandt V, De Strooper B, Nuttin B, Debyser Z: Gene therapeutic strategies for neurodegenerative diseases. Curr Opin Mol Ther 2000; 2:540-554.

90 Estibeiro P, Godfray J: Antisense as a neuroscience tool and therapeutic agent. Trends Neurosci 2001;24(suppl):S56-S62.

91 Hock C, Konietzko U, Papassotiropoulos A, Wollmer A, Streffer J, von Rotz RC, Davey G, Moritz E, Nitsch RM: Generation of antibodies specific for beta-amyloid by vaccination of patients with Alzheimer disease. Nat Med 2002;8:1270-1275. 